\title{
Combined evaluation of inhibin B, follicle stimulating hormone and luteinizing hormone improve sperm retrieval prediction in patients with non-obstructive azoospermia*
}

\author{
Bing Wang, Xunbin Huang ${ }^{\#}$ \\ Family Planning Research Institute, Tongji Medical College, Huazhong University of Science and Technology, Wuhan, China; \\ \#Corresponding Author: huangxb@mails.tjmu.edu.cn
}

Received 2 April 2013; revised 3 May 2013; accepted 15 May 2013

Copyright (c) 2013 Bing Wang, Xunbin Huang. This is an open access article distributed under the Creative Commons Attribution License, which permits unrestricted use, distribution, and reproduction in any medium, provided the original work is properly cited.

\begin{abstract}
Introduction: Non-invasive methods that can predict sperm recovery in patients with non-obstructive azoospermia (NOA) arouse interest of clinicians. The aim of this study was to evaluate the predictive value of sperm retrieval in NOA. Materials and Methods: In the retrospective study, fine needle aspiration (FNA) was performed on 306 patients with NOA at the department of andrology, Wuhan Tongji Reproductive Medical Hospital. Inhibin B, FSH and LH plasma levels were analyzed and sperms were retrieved in 67 of 306 cases (21.89\%). Results: There were statistically significant differences between successful and unsuccessful sperm recovery groups in terms of mean serum inhibin B, FSH and LH levels. The areas under the curve (AUC) of inhibin $\mathrm{B}, \mathrm{FSH}$ and $\mathrm{LH}$ were $0.696,0.729$ and 0.747 respectively, and the AUC for the combined value of the three hormones is $\mathbf{0 . 8 3 2}$. The cut-off points were $27.31 \mathrm{pg} / \mathrm{ml}, 11.68 \mathrm{IU} / \mathrm{L}$ and $4.04 \mathrm{IU} / \mathrm{L}$ for inhibin B, FSH and $\mathrm{LH}$ respectively. Conclusions: This study suggests that the combined evaluation of inhibin B, FSH and $\mathrm{LH}$ is a more effective predictor for successful sperm retrieval in patients with NOA before decision making of an invasive procedure than any single factor.
\end{abstract}

Keywords: Non-Obstructive Azoospermia; Sperm; Hormones; Prediction; Non-Invasive

\section{INTRODUCTION}

Before the introduction of intracytoplasmic sperm in-

"Conflict of Interest: Authors declare no conflict of interest. jection (ICSI [1], as to patients with NOA, there was no available treatment for them. Therefore, testicular sperm extraction has become a popular surgical procedure to obtain sperm in NOA patients [2]. The successful sperm recovery is observed in $40 \%-60 \%$ of these patients by Testicular Epididymal Sperm Extraction (TESE) [3,4]. In addition, TESE is an invasive procedure and may bring some side effects $[5,6]$ to the patients of sperm retrieval failure, and it may result in physical and financial complications. In order to avoid these unsuccessful results, some reasonable predictions are important to offer.

Fine needle aspiration (FNA) is a less invasive method. Bettella, A. et al. reported that the sensitivity and specificity of FNA were $44.6 \%$ and $100 \%$, respectively. They concluded that FNA might be a reliable diagnostic tool for successful sperm retrieval [6]. Although FNA can minimize damages, it is not wise to practice in all azoospermia patients. Other factors such as finance, side effects and compliance should be considered before decision making.

In order to prevent these complications, some reliable markers are needed to give a clue to clinicians that the cases for whom TESE or FNA would be suitable. In recent years, non-invasive exams such as hormonal parameters have been proposed. Inhibin B consisting of $\alpha$ subunit and $\beta$-subunit is a glycoprotein hormone mainly produced by the Sertoli cells [7]. Inhibin B has been proposed as a marker of spermatogenesis. Men with severe oligozoospermia and idiopathic azoospermia have significantly lower serum inhibin B levels than men with normospermia [8]. Spermatogenesis is also dependent on the balanced endocrine interaction [9]. FSH acts on receptors in Sertoli cells and initiate spermatogenesis, while luteinizing hormone (LH) stimulates the production of testosterone, which in turn may act on the seminiferous tu- 
bules and influence spermatogenesis [10]. It is indicated that both FSH and LH are necessary for the initiation of spermatogenesis [11].

Inhibin $\mathrm{B}, \mathrm{FSH}$ and $\mathrm{LH}$ are all close related to spermatogenesis, no matter whether they can predict the successful sperm recovery in testis in patients with NOA. Ziaee, S.A. et al. suggested that Serum FSH and inhibin $\mathrm{B}$ are useful predictors of the presence of sperm in patients with NOA. Combination of two parameters can improve the predictive power [12], though another study fails to conform this finding [13]. With a retrospective study using data from our hospital in recent five years, we assess the predictive values of the combined effect of inhibin B, FSH and LH before testicular sperm retrieval.

\section{MATERIALS AND METHODS}

\subsection{Patients}

This retrospective study included 306 patients with NOA. Patients with obstructive azoospermia were diagnosed by physical examination, while Seminal glycosidase test, or Vas Deferens Radiography or epididymal FNA were excluded. Patients with abnormal karyotypes were also excluded from the data. The diagnosis of azoospermia is on the basis of at least three semen analyses after centrifugation. The ages of the patients ranged from 21 - 42 yrs. Clinical, paraclinical, and histological information of patients were gathered and each subject was evaluated with fully physical examination.

\subsection{Hormonal Analyses}

Serum levels of inhibin B were measured in all patients by a solid-phase sandwich enzyme-linked immunosorbent assay (ELISA) (Serotec, Oxford, UK). FSH and LH were evaluated by immunofluorometric assays (Autodelfia, Wallac, Inc., Freiburg, Germany).

\subsection{Fine Needle Aspiration of Testes}

To perform testicular FNA, the area around the spermatic cord was locally anesthetized by injecting $5 \mathrm{ml}$ of $2 \%$ lidocaine after skin iodine disinfection. The aspiration was then performed in the center as well as in the upper and lower poles of each testis using a 20 Gauge needle with a $5 \mathrm{ml}$ syringe attached to it. A constant negative pressure was applied to the syringe when the needle reached the center of the testis and aspiration was done with gentle back and forth movements of the needle at different angles in each puncture location. The aspirated tissue from each location was placed on a separate slide, air-dried, and stained with May-Grünwald Giemsa.

FNA was performed in 306 patients with NOA just as previously described [14]. On the basis of FNA analysis, the subjects were divided into three cytological groups:
1) SCOS: Complete absence of spermatogenic cells in both testes; 2) Maturation arrest: Sperm maturation stopped in every stage of spermatogenesis; 3 ) severe hypospermatogenesis: The remarkable reduction in the number of germ cells. In a few cases, sperms can be retrieved in groups 2) and 3).

\subsection{Statistics}

Statistical analysis was performed with the SPSS 17. Mean values of hormones were compared with student- $t$ test. Two-sided $\mathrm{P}$ values less than 0.05 were regarded as statistic significant. The two groups of patients with or without sperm recovery were assessed by Receiver operating characteristic (ROC) analysis. A cut-off point for each hormonal was found by ROC. The area under the ROC curve, sensitivity and specificity were obtained from each model. The area under the ROC curve is a measure of the efficiency of the marker to predict sperm recovery.

\section{RESULTS}

Sperm extraction was successful in 67 and unsuccessful in 239 cases. There were statistically significant differences between successful and unsuccessful sperm recovery groups in terms of mean serum inhibin B, FSH and LH levels (Table 1). Serum inhibin B levels were significantly higher in the group of the successful sperm recovery $(64.59 \pm 26.05 \mathrm{pg} / \mathrm{ml})$ than the group of sperm recovery failure $(25.88 \pm 9.85 \mathrm{pg} / \mathrm{ml})(\mathrm{P}=0.019)$. The mean value of serum FSH in the group of patients with sperm recovery was $11.41 \pm 3.45 \mathrm{IU} / \mathrm{L}$ and in the group of without sperm recovery was $19.38 \pm 6.95 \mathrm{IU} / \mathrm{L}(\mathrm{P}=$ 0.006). Serum LH in different groups were $4.40 \pm 1.86$ $\mathrm{IU} / \mathrm{L}$ and $7.53 \pm 2.72 \mathrm{IU} / \mathrm{L}$, respectively $(\mathrm{P}=0.000)$.

The predictive value of inhibin $\mathrm{B}, \mathrm{FSH}, \mathrm{LH}$ and three of them were evaluated by ROC curve (Figure 1). The combination ROC curve represented combination of in hibin B, FSH and LH. As shown in Table 2, the areas under the curve (AUC) were 0.696 for inhibin B, 0.729 for FSH, and 0.747 for LH. The sensitivities and specificities were $66.7 \%$ and $67.5 \%$ for inhibin B, $74.3 \%$ and

Table 1. Mean serum hormone concentrations according to the outcome of FNA in men with non-obstructive azoospermia. There was statistically significant difference between successful and unsuccessful sperm recovery groups in terms of mean serum inhibin B, FSH and LH levels.

\begin{tabular}{cccc}
\hline \multicolumn{3}{c}{ sperm recovery } & P \\
\hline \multirow{4}{c}{ successful } & unsuccessful \\
inhibin B & $64.59 \pm 26.05$ & $25.88 \pm 9.85$ & 0.019 \\
FSH & $11.41 \pm 3.45$ & $19.38 \pm 6.95$ & 0.006 \\
LH & $4.40 \pm 1.86$ & $7.53 \pm 2.72$ & 0.000 \\
\hline
\end{tabular}



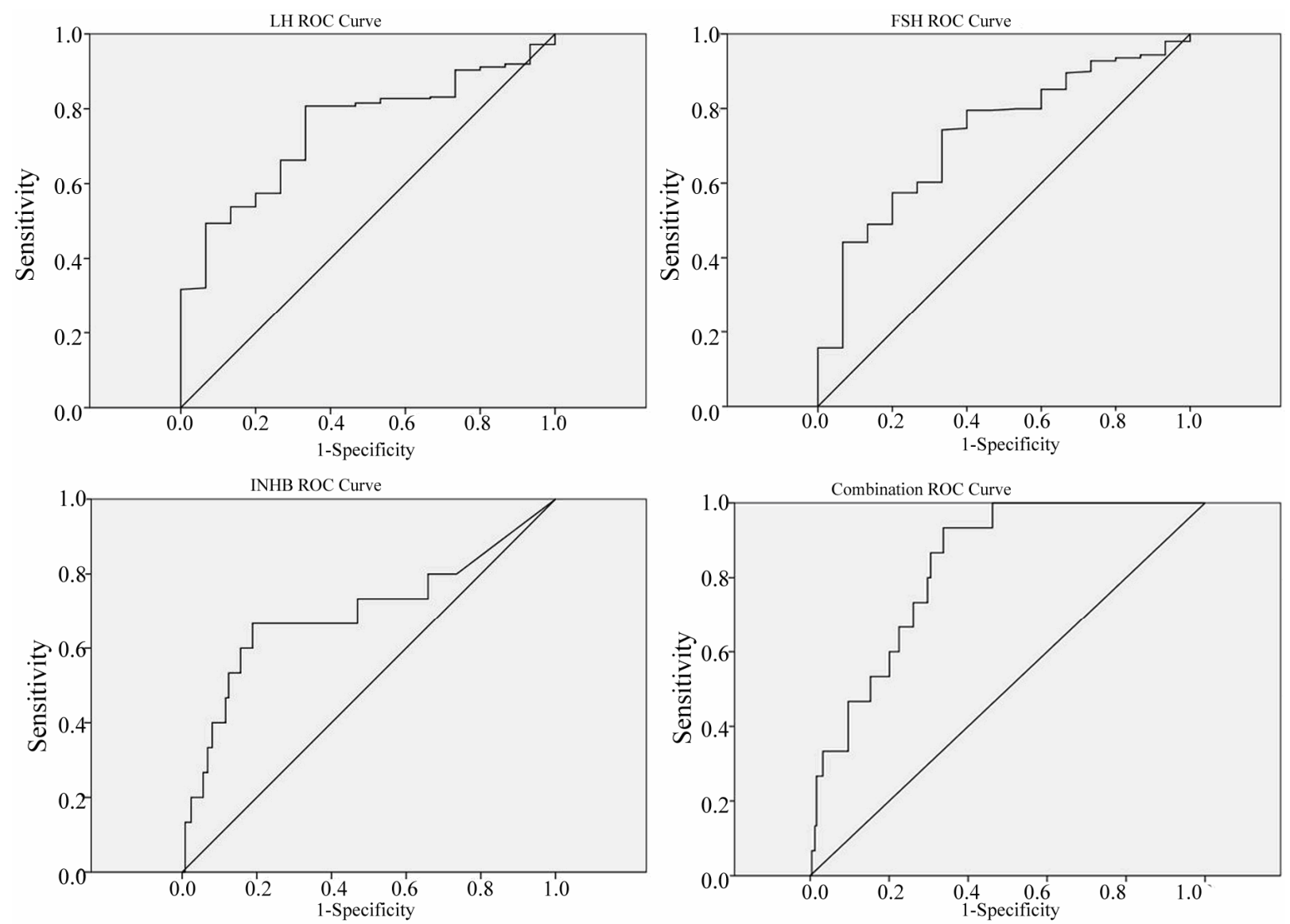

Figure 1. Receiver operating characteristic (ROC) curve of inhibin B, FSH, LH and combination of inhibin B, FSH and LH were evaluated. The areas under the curve (AUC) were 0.696 for inhibin B, 0.729 for FSH, 0.747 for LH and 0.832 for combination.

$66.7 \%$ for FSH, and $66.7 \%$ and $67.5 \%$ for $\mathrm{LH}$, respectively. The cut-off points were $27.31 \mathrm{pg} / \mathrm{ml}$ for inhibin B, 11.68 IU/L for FSH, and 4.04 IU/L for LH. When the predictive value of the combination of the three was assessed, we found that the area under the curve was 0.832 and the sensitivity and specificity were $93.30 \%$ and $66.30 \%$.

\section{DISCUSSION}

Recovery of sperms for ICSI is a crucial treatment for patients with NOA [2,15]. However, sperm retrieval techniques such as TESE and FNA are invasive procedures and associated with potential complications [16]. Financial, emotional stress and damage to testes due to unsuccessful biopsy have stimulated many researchers to find non-invasive methods to predict sperm recovery. In addition, a biopsy may not be representative of whole testis [16,17].

Even though it has been proposed that inhibin B be a marker of the functional state of the seminiferous epithelium [18], and FSH and LH are necessary for the initiation of spermatogenesis [11], the combined evaluation of
Table 2. Predictive value of inhibin B, FSH and LH for successful sperm retrieval in men with non-obstructive azoospermia. AUC: The area under the curve.

\begin{tabular}{cccc}
\hline & AUC & sensitivity & specificity \\
\hline inhibin B & 0.696 & $66.70 \%$ & $67.50 \%$ \\
FSH & 0.729 & $74.30 \%$ & $66.70 \%$ \\
LH & 0.747 & $66.70 \%$ & $67.50 \%$ \\
$\begin{array}{c}\text { inhibin B + FSH } \\
\text { + LH }\end{array}$ & 0.832 & $93.30 \%$ & $66.30 \%$ \\
\hline
\end{tabular}

these three parameters can strengthen the power of sperm recovery predict in patients with NOA. Because different views can be found in the literature, for example, Ballesca JL et al concluded that inhibin B and FSH are useful non-invasive predictors of sperm recovery and thus, all azoospermic males should have serum inhibin B and FSH concentrations measurement prior to undergoing TESE [19]. Whereas, Tunc, L. et al. failed to conform this finding [20]. Because inhibin B, FSH and LH are closely related to spermatogenesis, we have good reason to believe that those cases obtained sperms have relatively higher inhibin B and lower FSH and LH. Compared to 
the traditional open testicular biopsy, FNA is a quick, low cost, less invasive and reliable procedure [21]. We employed this method in 306 patients with NOA and had 67 cases of successful sperm recovery. The probability of sperm retrieval in our study was $21.89 \%$ that was lower than other study (such as $26.4 \%$ in the study of Bettella, A.). If we make a pre-operation evaluation of sperm recovery in terms of the combined parameters of inhibin $\mathrm{B}$, FSH and LH, the probability of sperm retrieval in FNA may increase.

In our study, there was statistically significant difference between successful and unsuccessful sperm recovery groups in terms of mean serum inhibin B, FSH and LH levels. But individual hormone is not reliable in prediction of sperm recovery before invasive procedures. In order to obtain more reliable prediction, ROC curve is used to evaluate the results. We found that the area under the curve of inhibin B, FSH and LH were 0.696, 0.729 and 0.747 respectively. When three of them were assessed together, we found that the area under the curve increased to 0.832 . The predictive power was significantly improved by the combination of inhibin B, FSH and $\mathrm{LH}$. The cut-off points were $27.31 \mathrm{pg} / \mathrm{ml}$ for inhibin B, $11.68 \mathrm{IU} / \mathrm{L}$ for FSH, and $4.04 \mathrm{IU} / \mathrm{L}$ for $\mathrm{LH}$. We noted that in the successful sperm recovery group, there were 58 of 67 (86.5\%) patients with a serum level of inhibin B $>27.31 \mathrm{pg} / \mathrm{mL}, \mathrm{FSH}<11.68 \mathrm{IU} / \mathrm{L}$, and $\mathrm{LH}<4.40 \mathrm{IU} / \mathrm{L}$. While in the unsuccessful sperm recovery group, only 4 of 239 (1.67\%) reached that level. The result can give a clue to clinical counseling. When the patients have a serum level of inhibin B $>27.31 \mathrm{pg} / \mathrm{mL}, \mathrm{FSH}<11.68$ $\mathrm{IU} / \mathrm{L}$, and $\mathrm{LH}<4.40 \mathrm{IU} / \mathrm{L}$ at the same time, the probability of sperm recovery is quite high. However, in other individuals with a serum level of inhibin $\mathrm{B}<27.31$ $\mathrm{pg} / \mathrm{mL}, \mathrm{FSH}>11.68 \mathrm{IU} / \mathrm{L}$, and $\mathrm{LH}>4.40 \mathrm{IU} / \mathrm{L}$ are not able to predict absence of sperm due to multifactor influence spermatogenesis in testes. So the cut-off points of these three hormones may be set up as a powerful predictor for successful sperm retrieval for patients with NOA. For patients whose values of inhibin B, FSH and LH are over the cut-off points, if sperm retrieval failed, we advise them to take open microsurgical biopsies.

\section{CONCLUSION}

In conclusion, though inhibin B, FSH and LH are useful predictors of sperm retrieval in patients with NOA, the combined evaluation of them would be more powerful in the predicting of successful sperm recovery for patients with NOA before decision making of FNA procedure.

\section{REFERENCES}

[1] Palermo, G., Joris, H., Devroey, P. and Van Steirteghem,
A.C. (1992) Pregnancies after intracytoplasmic injection of single spermatozoon into an oocyte. Lancet, 340, 1718. doi:10.1016/0140-6736(92)92425-F

[2] Devroey, P, Liu, J., Nagy, Z., Goossens, A., Tournaye, H., Camus, M., et al. (1995) Pregnancies after testicular sperm extraction and intracytoplasmic sperm injection in non-obstructive azoospermia. Human Reproduction, 10, 1457-1460. doi:10.1093/HUMREP/10.6.1457

[3] Su, L.M., Palermo, G.D., Goldstein, M., Veeck, L.L., Rosenwaks, Z. and Schlegel, P.N. (1999) Testicular sperm extraction with intracytoplasmic sperm injection for nonobstructive azoospermia: Testicular histology can predict success of sperm retrieval. Journal of Urology, 161, 112116. doi:10.1016/S0022-5347(01)62079-2

[4] Seo, J.T. and Ko, W.J. (2001) Predictive factors of successful testicular sperm recovery in non-obstructive azoospermia patients. International Journal of Andrology, 24, 306-310. doi:10.1046/j.1365-2605.2001.00307.x

[5] Beierdorffer, H. and Schirren, C. (1979) Peculiarities and side effects of testicular biopsy. Andrologia, 11, 311-319. doi:10.1111/j.1439-0272.1979.tb02212.x

[6] Bettella, A., Ferlin, A., Menegazzo, M., Ferigo, M., Tavolini, I.M., Bassi, P.F., et al. (2005) Testicular fine needle aspiration as a diagnostic tool in non-obstructive azoospermia. Asian Journal of Andrology, 7, 289-294. doi:10.1111/j.1745-7262.2005.00043.x

[7] Burger, H.G. (1993) Clinical review 46: Clinical utility of inhibin measurements. The Journal of Clinical Endocrinology \& Metabolism, 76, 1391-1396. doi:10.1210/jc.76.6.1391

[8] Pierik, F.H., Vreeburg, J.T., Stijnen, T., De Jong, F.H. and Weber, R.F. (1998) Serum inhibin B as a marker of spermatogenesis. The Journal of Clinical Endocrinology \& Metabolism, 83, 3110-3114.

doi:10.1210/jc.83.9.3110

[9] de Kretser, D.M. (1979) Endocrinology of male infertileity. British Medical Bulletin, 35, 187-192.

[10] O’Donnell, L., McLachlan, R.I., Wreford, N.G. and Robertson, D.M. (1994) Testosterone promotes the conversion of round spermatids between stages VII and VIII of the rat spermatogenic cycle. Endocrinology, 135, 26082614. doi:10.1210/en.135.6.2608

[11] Matsumoto, A.M. and Bremner, W.J. (1987) Endocrinology of the hypothalamic-pituitary-testicular axis with particular reference to the hormonal control of spermatogenesis. Baillière's Clinical Endocrinology and Metabolism, 1, 71-87. doi:10.1016/S0950-351X(87)80053-8

[12] Ziaee, S.A., Ezzatnegad, M., Nowroozi, M., Jamshidian, H., Abdi, H. and Hosseini, M.S. (2006) Prediction of successful sperm retrieval in patients with nonobstructive azoospermia. Journal of Urology, 3, 92-96.

[13] von Eckardstein, S., Simoni, M., Bergmann, M., Weinbauer, G.F., Gassner, P., Schepers, A.G., et al. (1999) Serum inhibin B in combination with serum follicle-stimulating hormone (FSH) is a more sensitive marker than serum FSH alone for impaired spermatogenesis in men, but cannot predict the presence of sperm in testicular tissue samples. The Journal of Clinical Endocrinology \& 
Metabolism, 84, 2496-2501. doi:10.1210/jc.84.7.2496

[14] Foresta, C. and Varotto, A. (1992) Assessment of testicular cytology by fine needle aspiration as a diagnostic parameter in the evaluation of the oligospermic subject. Fertility and Sterility, 58, 1028-1033.

[15] Tournaye, H., Camus, M., Goossens, A., Liu, J., Nagy, P., Silber, S., et al. (1995) Recent concepts in the management of infertility because of non-obstructive azoospermia. Human Reproduction, 10, 115-119.

[16] Schlegel, P.N. and Su, L.M. (1997) Physiological consequences of testicular sperm extraction. Human Reproduction, 12, 1688-1692. doi:10.1093/humrep/12.8.1688

[17] Tournaye, H., Verheyen, G., Nagy, P., Ubaldi, F., Goossens, A., Silber, S., et al. (1997) Are there any predictive factors for successful testicular sperm recovery in azoospermic patients? Human Reproduction, 12, 80-86. doi:10.1093/humrep/12.1.80

[18] Frydelund-Larsen, L., Krausz, C., Leffers, H., Andersson, A.M., Carlsen, E., Bangsboell, S., et al. (2002) Inhibin B: A marker for the functional state of the seminiferous epi- thelium in patients with azoospermia factor $\mathrm{C}$ microdeletions. The Journal of Clinical Endocrinology \& Metabolism, 87, 5618-5624. doi:10.1210/jc.2002-020737

[19] Ballesca, J.L., Balasch, J., Calafell, J.M., Alvarez, R., Fabregues, F., de Osaba, M.J., et al. (2000) Serum inhibin B determination is predictive of successful testicular sperm extraction in men with non-obstructive azoospermia. Human Reproduction, 15, 1734-1738. doi:10.1093/humrep/15.8.1734

[20] Tunc, L., Kirac, M., Gurocak, S., Yucel, A., Kupeli, B., Alkibay, T., et al. (2006) Can serum Inhibin B and FSH levels, testicular histology and volume predict the outcome of testicular sperm extraction in patients with nonobstructive azoospermia? International Urology and $\mathrm{Ne}$ phrology, 38, 629-635. doi:10.1007/s11255-006-0095-1

[21] Rosenlund, B., Kvist, U., Ploen, L., Rozell, B.L., Sjoblom, P. and Hillensjo, T. (1998) A comparison between open and percutaneous needle biopsies in men with azoospermia. Human Reproduction, 13, 1266-1271. doi:10.1093/humrep/13.5.1266 